\section{Endoscopic cholecystogastrostomy in a patient with gallbladder empyema secondary to cholangio- carcinoma}

Endoscopic ultrasound (EUS)-guided gallbladder drainage (EUS-GBD) is reported to have comparable efficacy to percutaneous drainage [1]. However, the technique has not been widely adopted owing to lack of specific devices and concerns about leakage and stent migration. Lumen-apposing metal stents have been developed to minimize the risks and simplify the procedure [2]. A novel device has recently become available (Hot AXIOS; Boston Scientific Corp., Marlborough, Massachusetts, USA), and consists of a stent (stent diameter $15 \mathrm{~mm}$, stent length $10 \mathrm{~mm}$, flange diameter $24 \mathrm{~mm}$ ) and electrocautery-enhanced delivery system, enabling a single device to be used when previously multiple devices and steps were required. To date, only a single case report of its use for EUS-GBD has been published [3]. We report on the use of this device for EUS-GBD in a 68-year-old woman with obstructive jaundice due to inoperable hilar cholangiocarcinoma.

A percutaneous transhepatic cholangiography procedure was performed, and an internal-external drain was placed. Shortly after this procedure the patient developed clinical features of cholecystitis. A computed tomography (CT) scan showed gross distension of the gallbladder and the presence of a gallbladder stone. There was also extensive pericholecystic fluid. Following a multidisciplinary team discussion, a decision was made to perform EUS-GBD using the Hot AXIOS.

The procedure was undertaken under conscious sedation, using a therapeutic echoendoscope. The gallbladder was punctured from the antrum using the

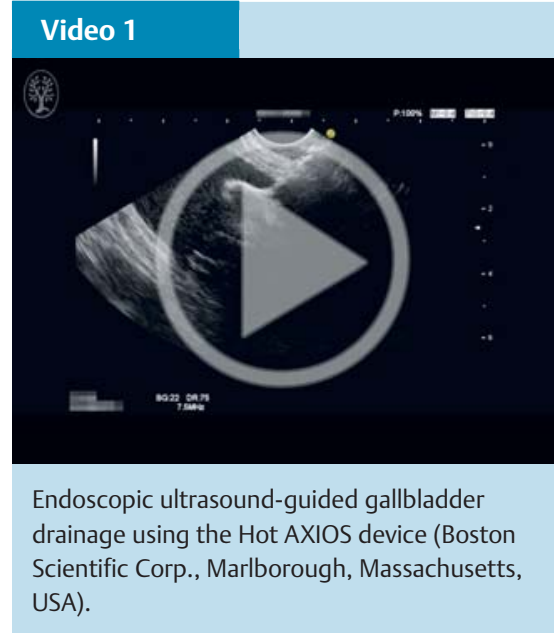

Hot AXIOS device and a cutting current was applied. Radiography was used, but deployment of the stent was entirely under EUS control ( $\bullet$ Video 1 ). The stent was dilated using a $10-\mathrm{mm}$ balloon. The procedure was well tolerated and completed within 15 minutes. EUS and fluoroscopy confirmed that the stent was in a good position. A large amount of pus drained immediately.

There was a rapid improvement in the patient's clinical condition over the next few days. Biliary drainage was internalized with the placement of two metal stents. CT scans at 8 days and 7 weeks post placement showed that the stent remained in the correct position and confirmed resolution of cholecystitis.

Endoscopy_UCTN_Code_TTT_1AS_2AD

Competing interests: None

\section{Bharat Paranandi ${ }^{1}$, Manu Nayar ${ }^{1}$, John Scott ${ }^{2}$, Richard Charnley ${ }^{3}$, Colin Wilson ${ }^{3}$, Kofi Oppong ${ }^{1}$}

${ }^{1}$ Department of Gastroenterology and HPB unit, Freeman Hospital, Newcastle upon Tyne, United Kingdom

2 Department of Radiology, Freeman Hospital, Newcastle upon Tyne, United Kingdom

${ }^{3}$ Department of Surgery and HPB unit, Freeman Hospital, Newcastle upon Tyne, United Kingdom

\section{References}

1 Jang JW, Lee SS, Song TJ et al. Endoscopic ultrasound-guided transmural and percutaneous transhepatic gallbladder drainage are comparable for acute cholecystitis. Gastroenterology 2012; 142: 805-811

2 Walter D, Teoh AY, Itoi $T$ et al. EUS-guided gall bladder drainage with a lumen-apposing metal stent: a prospective long-term evaluation. Gut 2016; 65: 6-8

3 Teoh AYB, Binmoeller KF, Lau JYW. Singlestep EUS-guided puncture and delivery of a lumen-apposing stent for gallbladder drainage using a novel cautery-tipped stent delivery system. Gastrointest Endosc 2014; 80 : 1171

Bibliography

DOI http://dx.doi.org/

10.1055/s-0042-106578

Endoscopy 2016; 48: E163

(c) Georg Thieme Verlag KG

Stuttgart - New York

ISSN 0013-726X

Corresponding author

Kofi Oppong, MD

Hepato-Pancreato-Biliary Unit

Freeman Hospital

Freeman Road

Newcastle upon Tyne NE7 7DN

United Kingdom

Fax: +44-191-2231249

Kofi.Oppong@nuth.nhs.uk 